Research report

\title{
Antidepressant-like effect of the mGluR5 antagonist MTEP in an astroglial degeneration model of depression
}

\author{
Helena Domin, Bernadeta Szewczyk, Monika Woźniak, \\ Anika Wawrzak-Wleciał, Maria Śmiałowska* \\ Department of Neurobiology, Institute of Pharmacology, Polish Academy of Sciences, Smętna 12, 31-343 Kraków, Poland
}

\section{H I G H L I G H T S}

- Astroglial degeneration in the rat prefrontal cortex as a model of depression.

- Gliotoxin L-AAA induced depressive-like behavior in the forced swim test.

- Antidepressant-like effect of mGluR5 antagonist MTEP in the gliotoxin model.

- Imipramine antidepressant activity in the gliotoxin model.

- MTEP and imipramine exerted glioprotective effects in L-AAA treated rats.

\section{A R T I C L E I N F O}

\section{Article history:}

Received 16 April 2014

Received in revised form 8 July 2014

Accepted 11 July 2014

Available online 18 July 2014

\section{Keywords:}

Gliotoxin

L-AAA

Depression

mGluR5 antagonist

MTEP

\begin{abstract}
A B S T R A C T
The glutamatergic predominance in the excitatory-inhibitory balance is postulated to be involved in the pathogenesis of depression. Such imbalance may be induced by astrocyte ablation which reduces glutamate uptake and increases glutamate level in the synaptic cleft. In the present study, we tried to ascertain whether astroglial degeneration in the prefrontal cortex could serve as an animal model of depression and whether inhibition of glutamatergic transmission by the mGluR5 antagonist MTEP could have antidepressant potential.

Astrocytic toxins L-or DL-alpha-aminoadipic acid (AAA), $100 \mu \mathrm{g} / 2 \mu \mathrm{l}$, were microinjected, bilaterally into the rat medial prefrontal cortex (PFC) on the first and second day of experiment. MTEP $(10 \mathrm{mg} / \mathrm{kg})$ or imipramine $(30 \mathrm{mg} / \mathrm{kg}$ ) were administered on the fifth day. Following administration of MTEP or imipramine the forced swim test (FST) was performed for assessment of depressive-like behavior. The brains were taken out for analysis on day eight. The astrocytic marker, glial fibrillary acidic protein (GFAP) was quantified in PFC by Western blot method and by stereological counting of immunohistochemically stained sections.

Both L-AAA and DL-AAA induced a significant increase in immobility time in the FST. This effect was reversed by imipramine, which indicates depressive-like effects of these toxins. A significant decrease in GFAP (about 50\%) was found after L-AAA. Both the behavioral and GFAP level changes were prevented by MTEP injection.

The obtained results indicate that the degeneration of astrocytes in the PFC by L-AAA may be a useful animal model of depression and suggest antidepressant potential of MTEP.
\end{abstract}

(C) 2014 Elsevier B.V. All rights reserved.

\section{Introduction}

A decrease in the density of glial cells in cortical regions, especially in the prefrontal and cingular areas was one of the most consistent findings from postmortem studies of brains of depressed patients [1-5]. Moreover, a decline in the number of astrocytes in

\footnotetext{
* Corresponding author. Tel.: +48 1266232 70; fax: +48 126374500 .

E-mail address: nfsmialo@cyf-kr.edu.pl (M. Śmiałowska).
}

the prefrontal cortex was observed in rats subjected to chronic unpredictable stress which is one of the generally accepted animal models of depression [6]. The main functions mediated by astrocytes include trophic support, neuronal differentiation and synaptic efficacy [7]. They regulate the local concentration of ions and neuroactive substances [8-12] which is crucial for keeping the central nervous system (CNS) homeostasis. Astrocytes are an integral part of tripartite synapse where they regulate neuronal excitability $[13,14]$. In the glutamatergic synapses, the most abundant type of synapses in the CNS, astrocytes control the levels of 
extracellular glutamate, the main excitatory neurotransmitter in the mammalian brain, so they maintain the excitatory/inhibitory balance there $[15,16]$.

It has been hypothesized lately that dysregulation of this balance underlies mood disorders and anxiety and that the glutamatergic predominance in this Glu/GABA balance is involved in the pathogenesis of depression [17-20]. Indeed, an increase in glutamate or glutamine level was documented in the brains and cerebrospinal fluid of depressed patients $[21,22]$ as well as in their plasma and platelets [23-25]. Moreover, the inhibition of glutamatergic function had antidepressant effects [26,27]. It was also found that chronic treatment with antidepressants caused the reduction of up-regulated glutamate release [28-30].

As mentioned above, astrocytes have a crucial role in maintaining the proper Glu/GABA balance, as they take up the released glutamate. Hence, the basic consequences of the disappearance or dysfunction of astrocytes include the reduction of glutamate uptake and thus excessive glutamate levels in the synaptic cleft which disturbs the balance and may lead to depression.

Recently, depressive-like behavior has been demonstrated in rats after degeneration of astrocytes by gliotoxins [6]. The authors postulated that astroglial degeneration induced by the astrocytic toxin L-alpha-aminoadipic acid (L-AAA) in the prefrontal cortex was sufficient to trigger depressive-like behavior. Previous studies of other authors performed in cell cultures and mice hypothalamus showed that not only L-AAA but also D-AAA and DL-AAA induced gliotoxic damage [31-34]. Therefore, in the present study we tried to find out whether such gliotoxins, not only L-AAA but also DL-AAA microinjected into the rat medial prefrontal cortex ( $\mathrm{MPFC}$ ), could serve as a new animal model of depression and whether our model of gliotoxin-induced depression may be useful for studying an antidepressant action of compounds. Moreover, we examined if both toxins decreased astrocytes density specifically in the prefrontal cortex. At the beginning, we verified if the classical antidepressant drug, imipramine, antagonized depressive-like effects of the gliotoxins and then we studied the effect of a compound engaged in the regulation of glutamatergic transmission.

As mentioned above, the overactivation of glutamatergic function in the prefrontal and limbic cortices may be essential in the pathophysiology of depression [35]. It was confirmed by the results in which inhibition of glutamatergic activity by NMDA receptor antagonists exerted antidepressant-like effects in laboratory animals [36,37] and had antidepressant properties in depressed patients [38-41]. Ketamine is the first drug of clinical significance which has a mechanism of action associated with the NMDA receptor. This NMDA antagonist exhibits a rapid onset of action and has high therapeutic efficacy. Unfortunately, the high antidepressant activity of ketamine is associated with a risk of serious adverse effects (dissociative and psychotomimetic effects and the potential to abuse) that greatly restrict its application on a larger scale [42]. Since the therapeutic use of direct NMDA receptor antagonism is diminished by their undesirable side-effects, therefore, an indirect inhibition of glutamatergic function via metabotropic glutamate receptors (mGluR) seems to be a much more promising way for treatment of depression than the direct blockade of ionotropic glutamatergic receptors (iGluR). Indeed, mGluR ligands were demonstrated to produce antidepressant-like and anxiolytic effects. Metabotropic GluRs constitute a family of eight subtypes subdivided into three groups on the basis of sequence homology, pharmacological profile and transduction pathways [43]. Group I comprises mGluR1 and mGluR5 are primarily localized postsynaptically and are positively coupled with phosphoinositide hydrolysis, activation of phospholipase $C$, protein kinase $C$ and calcium release [44]. Many studies showed that stimulation of these receptors potentiated the excitatory effect of glutamate by modulation of ion channels [45], while blockade of these receptors attenuated these excitatory effects. Behavioral studies in the last years have revealed that group I mGluR antagonists produced antidepressant-like activity in several tests and models in rodents. Recently, MTEP (3-[(methyl-1,3-thiazol-4-yl)ethynyl]pyridine), a highly selective, non-competitive antagonist of metabotropic glutamate receptors subtype 5 (mGluR5), has been described as an antidepressant and anxiolytic compound in animal experiments in the behavioral despair tests and in the bulbectomyinduced model of depression [46-50]. Moreover, in our previous studies we found neuroprotective effect of MTEP which was related to the inhibition of glutamatergic transmission and glutamate release [51].

Therefore, the goal of the present study was to find out if the mGluR5 antagonist MTEP may have potential antidepressant effects in the astrocytic toxin-induced rat model of depression. Such supposition seems to be reasonable as an overactivation of glutamate activity which is postulated to occur in gliotoxic model may be inhibited by MTEP.

\section{Materials and methods}

\subsection{Animals}

Male Spraque-Dawley rats (Charles River, Germany) weighing about $250-300 \mathrm{~g}$ at the beginning of the experiment, were used in the study. The animals were kept under standard laboratory conditions of constant temperature $\left(19-21^{\circ} \mathrm{C}\right)$, controlled 12:12 light-dark cycle. The rats were age-matched and were housed six to a cage on a 12:12 light-dark cycle, with free access to food and tap water. The rats after cannulae implantation were housed singly. During the experiment, all efforts were made to minimize animal suffering and to reduce the number of animals used, in accordance with the Local Bioethical Commission Guide for the Care and Use of Laboratory Animals.

\subsection{Cannulae implantation}

The rats anaesthetized with ketamine $(75 \mathrm{mg} / \mathrm{kg}$ i.m.) and xylazine ( $10 \mathrm{mg} / \mathrm{kg}$ i.m.) were stereotaxically, bilaterally implanted with guide cannulae aimed at the medial prefrontal cortex (mPFC) region using the following coordinates: $A P=+3.2 \mathrm{~mm}, L=+1.0 \mathrm{~mm}$ from the Bregma, $H=-3.5 \mathrm{~mm}$ from the skull, according to the Paxinos and Watson stereotaxic atlas [52]. The guide cannulae (23-gauge stainless steel tubing), secured by dental cement, were anchored to the skull by three stainless steel screws. In order to prevent clogging, stainless steel stylets were placed in the guide cannulae and left until the animals were microinjected. Animals were left for 7 days for recovery.

\subsection{Drug treatments}

On the 1 st and 2nd day of the experiment, the rats were bilaterally microinjected into medial prefrontal cortex (mPFC) with astrocytic toxins L-alpha-aminoadipic acid (L-AAA), or DLalpha aminoadipic acid (DL-AAA) (Sigma-Aldrich Chemie GmbH, Germany). The gliotoxins were freshly dissolved in $0.1 \mathrm{M}$ phosphate buffer, pH 7.4 and were microinjected at doses of $100 \mu \mathrm{g} / 2 \mu \mathrm{l}$. Control rats were bilaterally injected with a phosphate buffer. Afterwards depressive-like behavior was assessed by a forced swim test (FST) $24 \mathrm{~h}, 72 \mathrm{~h}$ or $144 \mathrm{~h}$ after the second gliotoxins or buffer administration in the time course experiment, and $72 \mathrm{~h}$ (on day 5 ) in all other experiments. The other group of rats was additionally treated with the antidepressant imipramine hydrochloride (Sigma-Aldrich Chemie GmbH, Germany) in a dose of $30 \mathrm{mg} / \mathrm{kg}$, three times: 24, 5 and $1 \mathrm{~h}$ before the forced swim test (FST) or with mGluR5 antagonist MTEP (Tocris, USA) in a dose $10 \mathrm{mg} / \mathrm{kg}$, once 


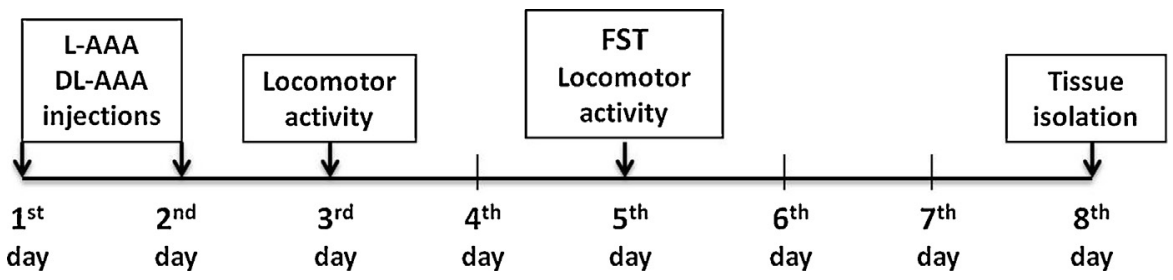

Fig. 1. Experimental design: schedule of treatments and tests in the gliotoxin model. Arrows indicate the time of treatments and tests on the timeline.

20 min before the FST. Imipramine was dissolved in saline, MTEP was suspended in $0.5 \%$ methylcellulose and both compounds were administered intraperitoneally (i.p.) in a volume of $2 \mathrm{ml} / \mathrm{kg}$. The schedule of treatment is shown at Fig. 1.

\subsection{Behavioral studies}

\subsubsection{Forced swim test (FST)}

The rats were subjected to the FST according to the method described in the paper of Nowak et al. [53]. Briefly, during the pretest the rats were placed individually in a glass cylinders $(40 \mathrm{~cm}$ high, $18 \mathrm{~cm}$ in diameter) containing $15 \mathrm{~cm}$ of water, maintained at $25^{\circ} \mathrm{C}$. After $15 \mathrm{~min}$ swimming session rats were removed from the cylinders and returned to their home cages. Rats were placed again in the cylinder $24 \mathrm{~h}$ later and the total duration of immobility was measured during a $5 \mathrm{~min}$ test. Rats were judged to be immobile when it remained floating passively in the water. The effect of LAAA or DL-AAA alone and in combination with imipramine or MTEP was measured $72 \mathrm{~h}$ after the second administration of toxins. To obtain a time course effect of L-AAA administration in the FST, the total duration of immobility in rats was measured in the separated groups 24,72 and $144 \mathrm{~h}$ after the second L-AAA administration.

\subsubsection{Locomotor activity}

Locomotor activity was recorded individually for each animal in Opto-Varimex cages (Columbus Instruments, USA) linked on-line to a compatible IBM-PC. The behavior of the rats was analyzed using Auto-Track software (Columbus Instruments, Columbus, USA). Each cage $(43 \mathrm{~cm} \times 43 \times 21 \mathrm{~cm})$ was equipped with a $15 \times 15$ array of infrared emitters located $3 \mathrm{~cm}$ from the floor surface. The number of light beams interrupted by an animal was recorded at $5 \mathrm{~min}$ intervals and was presented as the distance traveled in $\mathrm{cm}$. Locomotor activity was recorded 24 or $72 \mathrm{~h}$ after the second gliotoxin administration; $1 \mathrm{~h}$ after the last dose of imipramine or 20 min after MTEP injection.

\subsubsection{Statistical analysis}

The obtained data were presented as means \pm SEM, and evaluated either by a two-way ANOVA analysis of variance, followed by Bonferroni multiple comparison test (results on Figs. 2 and 4) or Student's $t$-test (results on Fig. 3). The level of significance was determined as $p<0.05$.

\subsection{Western blot analysis}

On day eighth ( $144 \mathrm{~h}$ after the second gliotoxin injection) the rats were decapitated, brains were taken out and the glial fibrillary acidic protein (GFAP) level was determined in the prefrontal cortex (PFC), hippocampus, amygdala and posterior cortical areas. Prefrontal cortex was taken by cutting the anterior part of the forebrain at the level of Bregma $2.20 \mathrm{~mm}$ according to the Paxinos and Watson stereotaxic atlas [52]. Olfactory bulbs and the anterior striatum were cut off. Therefore, the tissue taken for analysis contained majority of the prefrontal cortex. Additionally NeuN protein level

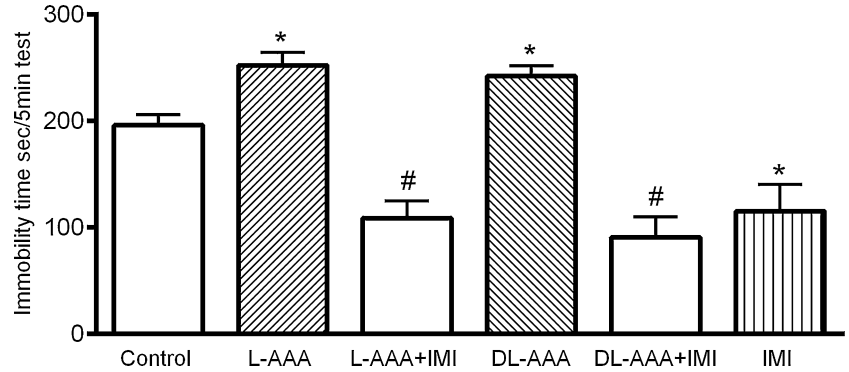

Fig. 2. The effect of combined administration of L-AAA, DL-AAA and imipramine (IMI) on the total duration of immobility in the FST in rats. L-AAA and DL-AAA were administered twice into the rat mPFC, at a dose of $100 \mu \mathrm{g} / 2 \mu \mathrm{l}$, on the first and the second day of experiment. The FST was performed on day 5 ( $72 \mathrm{~h}$ after the second injection). Imipramine ( $30 \mathrm{mg} / \mathrm{kg}$ ) was administered i.p., tree times: 24,5 and $1 \mathrm{~h}$ before the test. The obtained data were presented as the means \pm SEM ( $n=10-12$ rats per group) and evaluated by two-way ANOVA, followed by Bonferroni multiple comparison test. ${ }^{*} p<0.05$ vs control; ${ }^{*} p<0.001$ vs L-AAA or DL-AAA treated group.

(biomarker for neurons) was estimated after L-AAA injection in the PFC.

The tissue was homogenized in 2\% SDS and centrifuged for $5 \mathrm{~min}$ at $10,000 \mathrm{rpm}$ at $4{ }^{\circ} \mathrm{C}$. Protein concentration in the obtained supernatant was determined using a BCA Protein Assay Kit (Pierce). The samples containing $30 \mu \mathrm{g}$ of protein were separated by $10 \%$ SDS-polyacrylamide gel electrophoresis and transferred to nitrocellulose membranes using an electrophoretic transfer system. Non-specific binding was blocked for $30 \mathrm{~min}$ in blocking reagent (Roche). Then, membranes were incubated overnight at $4{ }^{\circ} \mathrm{C}$ with mouse monoclonal anti-GFAP antibody (1:5000, Millipore) or antiNeuN (1:1000, Millipore). The membranes were then washed with TBS-T and incubated for $30 \mathrm{~min}$ with a horseradish peroxidaseconjugated anti-mouse IgG secondary antibody (1:1000, Roche). The reaction was visualized by using BM Chemiluminescence Western Blotting Kit, Roche). Chemiluminescence was recorded and evaluated with a luminescent image analyzer (FUJI-LAS-4000). The

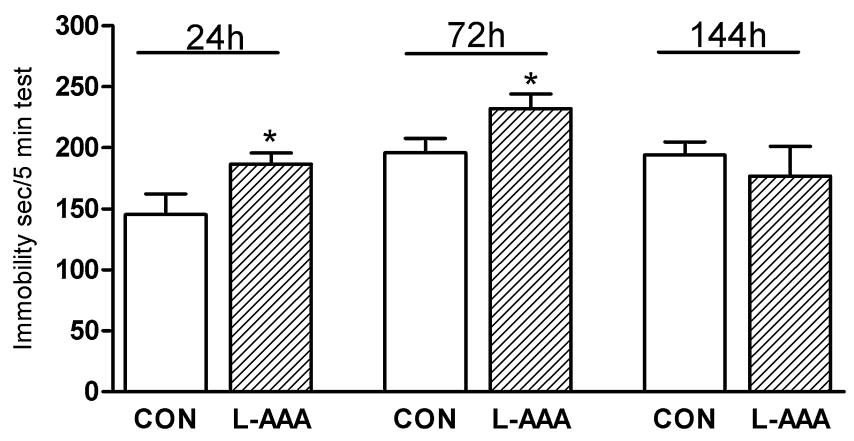

Fig. 3. The effect of L-AAA administration on the total duration of immobility in the FST in rats at different time points. L-AAA was administered twice into the rat mPFC at a dose of $100 \mu \mathrm{g} / 2 \mu \mathrm{l}$, on the first and the second day of experiment. The FST was performed 24,72 and $144 \mathrm{~h}$ after the second toxin injection. The obtained data were presented as the means \pm SEM ( $n=10-12$ rats per group) and evaluated by Student's $t$-test. Significance was assumed at $p<0.05$. 


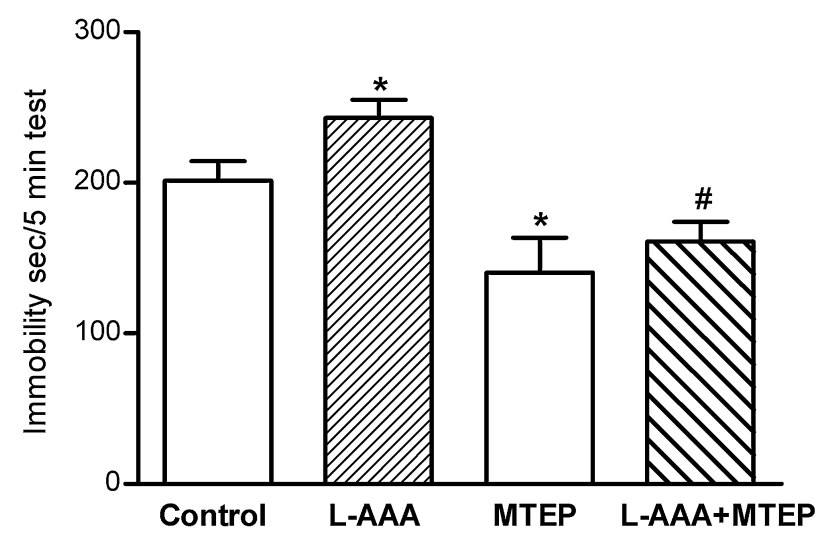

Fig. 4. The effect of combined administration of L-AAA and MTEP on the total duration of immobility in the FST in rats. L-AAA was administered twice into the rat mPFC at a dose of $100 \mu \mathrm{g} / 2 \mu \mathrm{l}$, on the first and the second day of experiment and MTEP, $10 \mathrm{mg} / \mathrm{kg}$, i.p., was given $20 \mathrm{~min}$ before the FST. The obtained data were presented as the means \pm SEM ( $n=10-12$ rats per group) and evaluated by two-way ANOVA, followed by Bonferroni multiple comparison test. ${ }^{*} p<0.05$ vs control; ${ }^{*} p<0.001$ vs L-AAA treated group.

relative levels of immunoreactivity were quantified using Image Gauge v 4.0 software. To confirm equal loading of the samples on the gel, the blots were incubated with mouse anti- $\beta$-actin antibody (1:5000, Sigma) and then processed as described above. The density of GFAP protein band was normalized to the density of the $\beta$-actin.

The Western blot analysis of GFAP was performed in group of rats treated with L-AAA, DL-AAA, L-AAA + imipramine, DLAAA + imipramine, imipramine, MTEP and L-AAA + MTEP. For the time course effect of L-AAA on GFAP and NeuN protein level in the PFC, rats were decapitated and the brains were collected 24,48 and $72 \mathrm{~h}$ after the second injection of gliotoxin. Western blot analysis was performed as described above.

\subsubsection{Statistical analysis}

The obtained data were presented as means \pm SEM, and evaluated either by a two-way ANOVA analysis of variance, followed by Bonferroni multiple comparison test (results on Figs. 6 and 7) or Student's t-test (results on Fig. 5). The level of significance was determined as $p<0.05$.

\subsection{Histological and immunohistochemical studies}

On day eighth (144h after the second injection of the toxin) the brains were taken for analysis. Rats under deep pentobarbital anesthesia were perfused through the ascending aorta with $0.9 \%$ physiological saline, followed by a cold $4 \%$ paraformaldehyde (PF) in $0.1 \mathrm{M}$ sodium phosphate buffer, $\mathrm{pH}$ 7.4. Next, their brains were removed, postfixed in cold buffered $\mathrm{PF}$ for $3 \mathrm{~h}$, and cryoprotected in a buffered $20 \%$ sucrose solution for at least 5 days at $4{ }^{\circ} \mathrm{C}$. The brains were then frozen on dry ice, and $40 \mu \mathrm{m}$ coronal sections were cut at levels containing medial prefrontal cortex (between bregma 4.70 to $1.70 \mathrm{~mm}$, according to the Paxinos and Watson stereotaxic atlas [52]. Free-floating sections were collected and every sixth section were taken for glial fibrillary acidic protein (GFAP) immunohistochemical staining, using anti-GFAP mouse monoclonal antibody (Millipore) diluted at 1:800 in sodium phosphate-buffer (PBS) containing $0.2 \%$ Triton X-100 and $1 \%$ normal horse serum. Adjacent sections were stained with cresyl violet and used for a histological analysis and verification of the injection sites. The immunostained sections, after reaction with primary antibody were rinsed in PBS and processed by an avidin-biotin peroxidase complex method using an $\mathrm{ABC}$-peroxidase kit (Vector Lab) and diaminobenzidine
A.
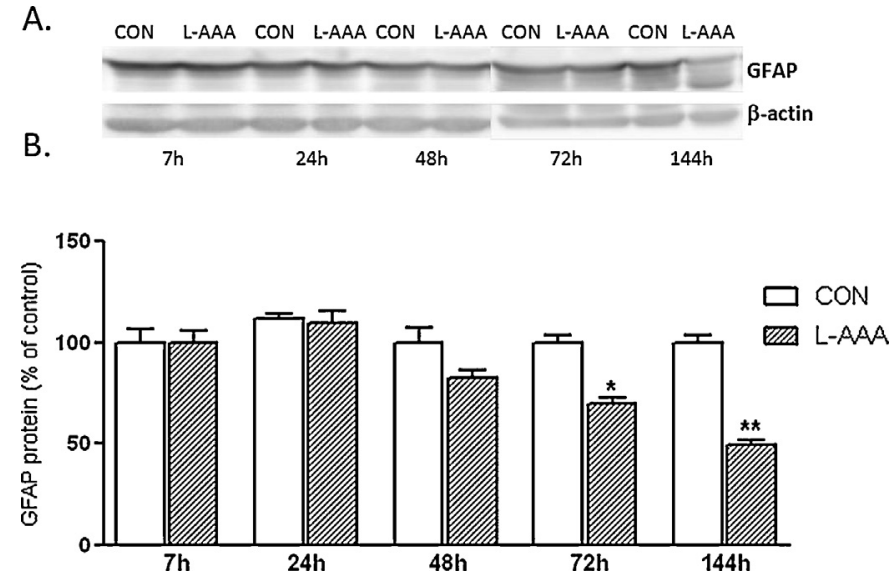

Fig. 5. The effect of L-AAA administration on the GFAP level in the rat PFC, measured at different time points. Western blot analysis. L-AAA was administered twice into the rat mPFC at a dose of $100 \mu \mathrm{g} / 2 \mu \mathrm{l}$, on the first and the second day of experiment. The GFAP level in the prefrontal cortex (PFC) was determined $7 \mathrm{~h}, 24 \mathrm{~h}, 48 \mathrm{~h}, 72 \mathrm{~h}$ and $144 \mathrm{~h}$ after the second toxin injection. (A) The immunoblot bands corresponding to GFAP (upper panels) and $\beta$-actin (lower panels) are seen. A weaker intensity of the GFAP band is observed in samples taken from rats 72 and $144 \mathrm{~h}$ after the L-AAA injection. (B) Analysis of data of the GFAP level. The obtained data were presented as the means \pm SEM ( $n=6-7$ rats per group) and evaluated by a Student's $t$-test. ${ }^{*} p<0.05,{ }^{* *} p<0.01$ vs control.

(DAB) as a chromogen. The stained sections were mounted on slides, dried, dehydrated, cleared in xylene, cover-slipped with Permount and analyzed under a light microscope.

Additionally, some sections from each group were stained by immunofluorescence method using anti-GFAP antibody. After $1 \mathrm{~h}$ incubation in a blocking buffer (5\% normal donkey serum and $0.2 \%$ Triton $\mathrm{X}-100$ in $0.01 \mathrm{M} \mathrm{PBS}$ ) the sections were incubated $\left(48 \mathrm{~h}\right.$ at $4{ }^{\circ} \mathrm{C}$ ) with the primary anti-GFAP mouse antibody (Millipore) diluted at 1:800 in the blocking buffer. After incubation with the primary antibody, the sections were washed and incubated overnight at $4{ }^{\circ} \mathrm{C}$ in the secondary antibody Cy3-conjugated anti-mouse IgG (1:200, Jackson ImmunoResearch, USA). The sections were then washed and mounted with a coverslip overlay. The

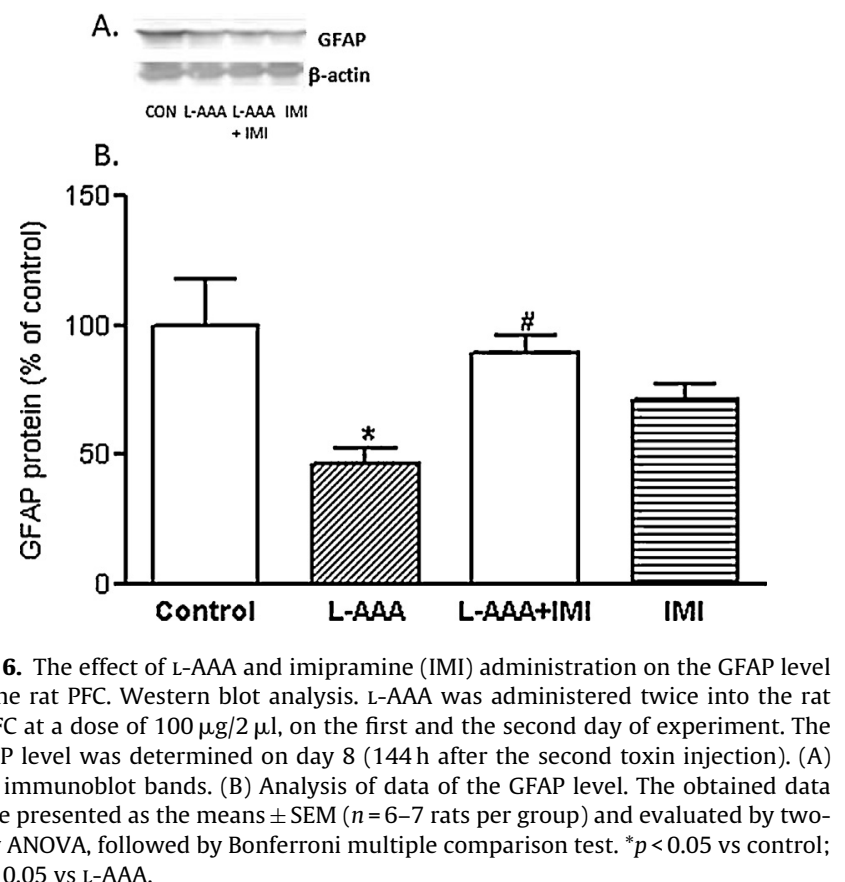


A.

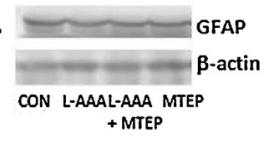

B.

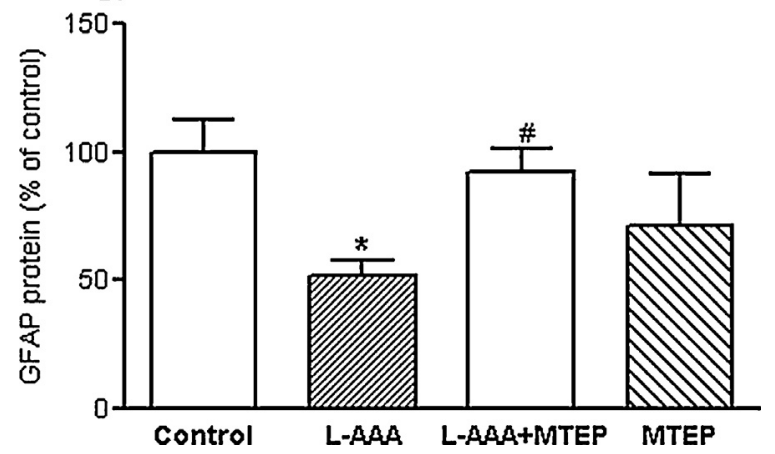

Fig. 7. The effect of L-AAA and MTEP administration on the GFAP level in the rat PFC. Western blot analysis. L-AAA was administered twice into the rat $\mathrm{MPFC}$ at a dose of $100 \mu \mathrm{g} / 2 \mu \mathrm{l}$, on the first and the second day of experiment. The GFAP level was determined $144 \mathrm{~h}$ after the second toxin injection. (A) The immunoblot bands. (B) Analysis of data of the GFAP level. The obtained data were presented as the means \pm SEM ( $n=6-7$ rats per group) and evaluated by two-way ANOVA, followed by Bonferroni multiple comparison test. ${ }^{*} p<0.05$ vs control; ${ }^{*} p<0.05$ vs L-AAA.

sections were analyzed with a confocal laser scanning microscope, DMRXA2 TCS SP2 (Leica), with a $63 \times / 1.40-0.70$ oil objective (Leica) driven by confocal software (Leica) using the sequential scan settings, as described previously [54]. Working with GreNe laser line emitting at $543 \mathrm{~nm}$ was used to excite Cy3-conjugated antibody. The background noise of each confocal image was then reduced by averaging four scans/line and six frames/image. The pinhole value of one airy was used to obtain flat images.

\subsection{Stereological counting of GFAP-immunoreactive astrocytes}

The number of GFAP-immunoreactive astrocyte cell bodies stained with $\mathrm{DAB}$, in the medial prefrontal cortex ( $\mathrm{MPFC}$ ) was evaluated by stereological counting. The procedures were performed using a microscope (Leica, DMLB; Leica, Denmark) equipped with a projecting camera (Basler Vision Technologies, Germany) and a microscope stage connected to an xyz stepper (PRIOR ProScan) controlled by a computer using Visiopharm New CAST software (Visiopharm, Denmark).

Systemic uniform, random sampling was used to choose the sections for the analysis. For stereological estimates, GFAPir astrocytes were counted within the contours of the MPFC $[\mathrm{AP}=4.70-1.70 \mathrm{~mm}]$ from bregma according to the Paxinos and Watson stereotaxic atlas [52] in at least 8-12 sections at $240 \mu \mathrm{m}$ intervals. The mPFC was outlined under a lower magnification $(5 x)$ and uniformly sampled dissector points were used at random along the whole structure using the meander sampling.

The total number of GFAP-positive cells in the mPFC was unbiasedly estimated using a three dimensional probe under a higher magnification $(63 \times)$ according to the formula: $N=\Sigma Q \times V($ ref $) / v($ dis $) \times \Sigma P$, where $\Sigma Q$ is a total count of GFAP-ir astrocytes in the uniformly sampled dissectors, $V($ ref $)$ - the total volume of the mPFC, $v$ (dis) - the total volume of the dissector [55] and $\Sigma P$ - the total number of all dissector points. A counting frame of $74.61 \mu \mathrm{m} \times 74.61 \mu \mathrm{m}\left(5567.27 \mu \mathrm{m}^{2}\right)$, a sampling grid of $333.68 \mu \mathrm{m} \times 333.68 \mu \mathrm{m}\left(111,342.3 \mu \mathrm{m}^{2}\right)$ and a dissector height of $20 \mu \mathrm{m}$ below the surface were employed. Sampling was optimized to produce a coefficient of error well under the observed biological variability [56]. The total volume of the mPFC $V$ (ref) was estimated using Cavalieri's principle [56] according to the formula:
$V($ ref $)=t \times a(p) \times \Sigma P$, where $t$ is the known distance between the sampled sections, $a(p)$ is the area associated with each point of a grid, $\Sigma P$ is the total number of counted points over all sections from one rat.

\subsubsection{Statistical analysis}

The data were presented as means \pm SEM, and evaluated by a one-way ANOVA analysis of variance, followed by Tukey's multiple comparison test. The level of significance was determined as $p<0.05$.

\section{Results}

\subsection{Behavioral studies}

\subsubsection{Effect of combined administration of L-AAA or DL-AAA and imipramine in the FST}

The effect of L-AAA and DL-AAA on the total duration of the immobility time in the FST in rats is shown in Fig. 2. L-AAA and DL-AAA administered twice into the rat MPFC, at a dose of $100 \mu \mathrm{g} / 2 \mu \mathrm{l}$, induces depressive-like behavior in the FST. The immobility time of rats increased significantly both in L-AAA and DL-AAA treated group as compared to control group. Administration of imipramine significantly decreased the immobility time of rats and antagonized the effects elicited by L-AAA and DLAAA administration. Two way ANOVA demonstrated significant effect of gliotoxin $[F(2,47)=3.32, p=0.0448]$; significant effect of imipramine $[F(1,47)=83.87, p=0.0001]$ and significant interaction $[F(2,47)=4.03, p=0.0242]$.

\subsubsection{Effect of $\mathrm{L}-A A A$ in the FST at different time points}

The time course effect of L-AAA on the total duration of the immobility time in the FST in rats is shown in Fig. 3. Depressivelike behavior, observed as increased immobility time in the FST was found $24 \mathrm{~h}(p=0.0445)$ and $72 \mathrm{~h}(p=0.0491)$ but not $144 \mathrm{~h}$ $(p=0.5103)$ after the second gliotoxin injection.

\subsubsection{Effect of combined administration of $\mathrm{L}-A A A$ and MTEP in the FST}

The effect of combined administration of L-AAA and MTEP on the total duration of the immobility time in FST in rats is shown in Fig. 4. L-AAA administered alone significantly increased the immobility time in FST. MTEP given alone significantly decreased the immobility time in rats and antagonized the effect induced by L-AAA. Two way ANOVA demonstrated the significant effect of MTEP $[F(1,39)=13,49, p=0.0007]$, significant effect of L-AAA $[F(1,39)=5.44, p=0.0249]$ and significant interaction $[F(1,39)=4.21, p=0.047]$.

\subsubsection{Effect of $\mathrm{L}-A A A$ and $\mathrm{DL}-A A A$ alone or in combined administration with imipramine and MTEP on the locomotor activity in rats}

The effect of L-AAA and DL-AAA administration alone or in combined treatment with imipramine and MTEP on the locomotor activity in rats is shown in Table 1.

L-AAA and DL-AAA administered alone did not influence the locomotor activity in rats (Table $1 \mathrm{~A}$ ). However, the imipramine alone or in combined administration with L-AAA and DL-AAA significantly decreased the locomotor activity in rats, measured $72 \mathrm{~h}$ after the second injection of toxin (Table 1B). No significant effect on the locomotor activity was found after MTEP and combined L-AAA and MTEP injections. Only a tendency for decrease was observed (Table 1C). Two way ANOVA demonstrated no effect of gliotoxins $F(2,25)=1.01, p=0.3802$, significant effect of 


\section{CON}
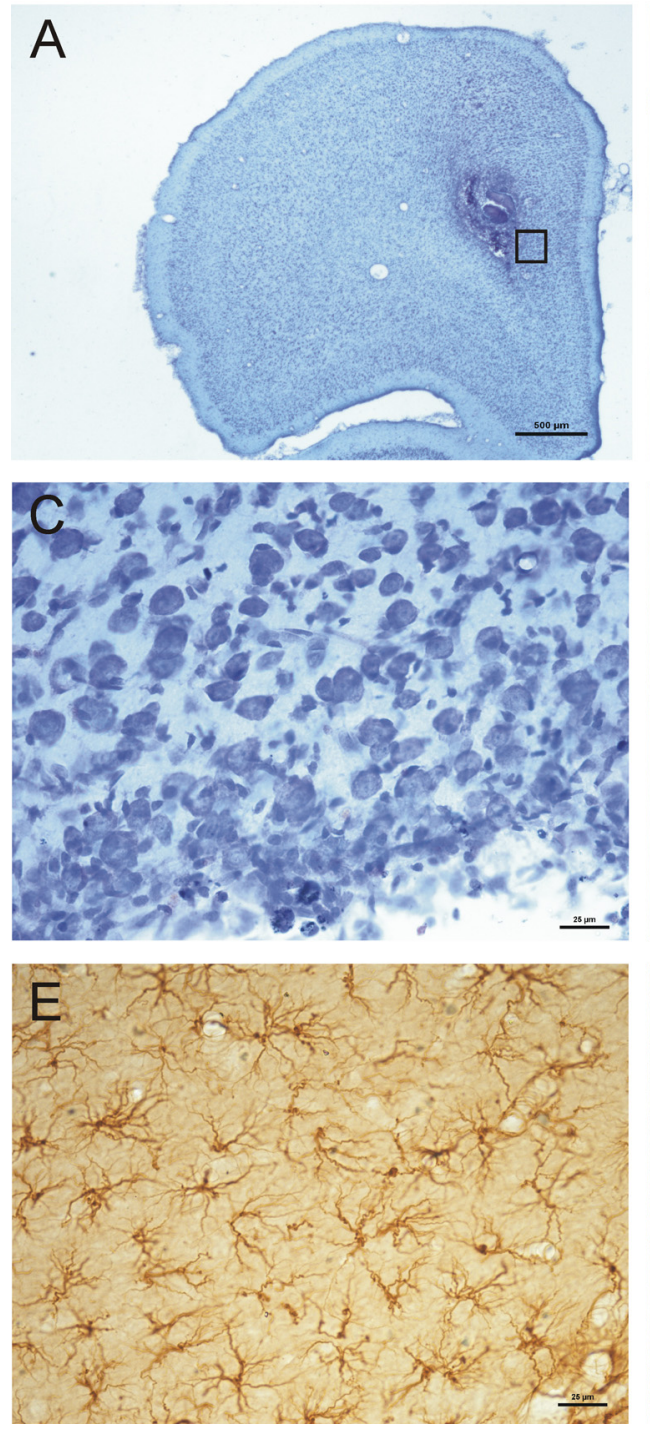

LAAA
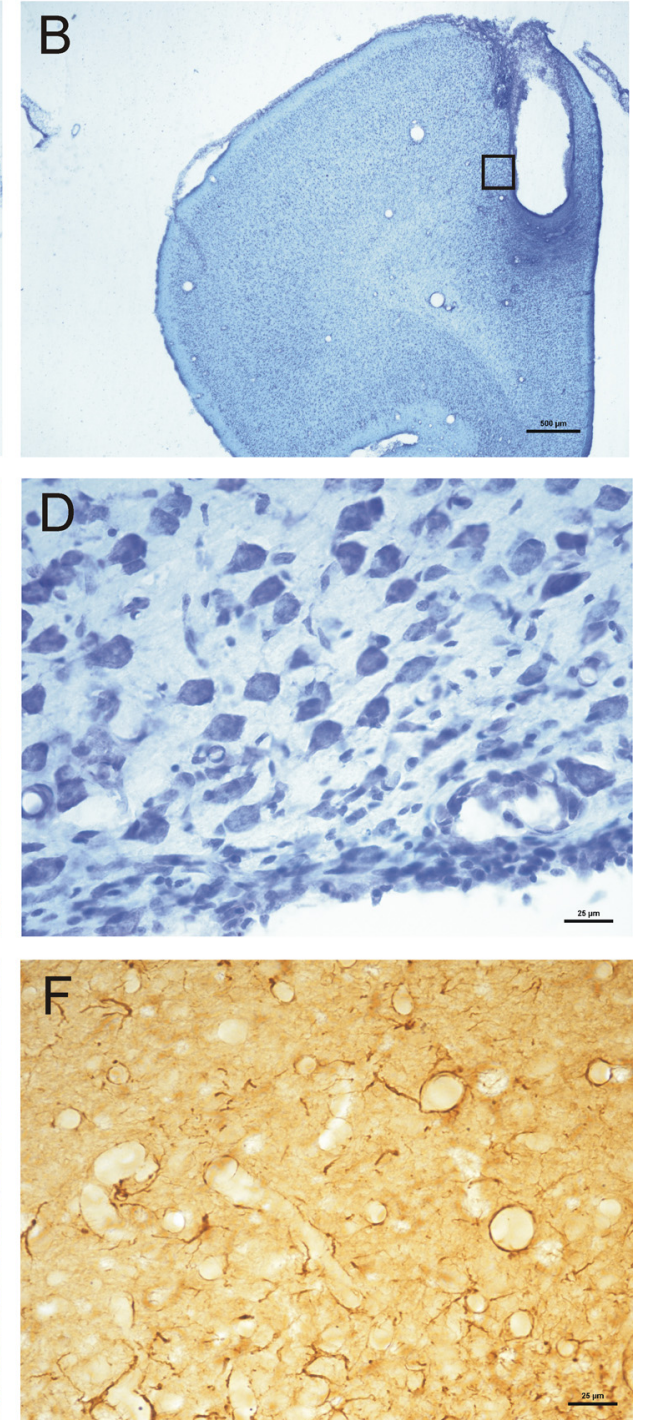

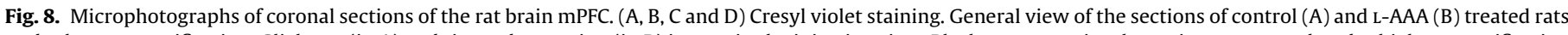

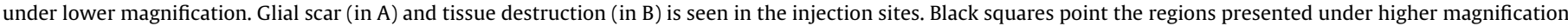

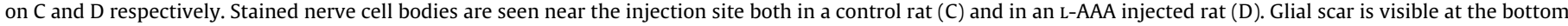

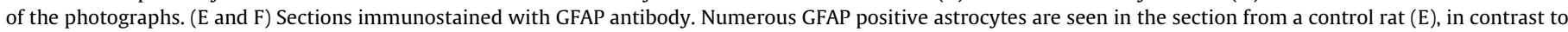

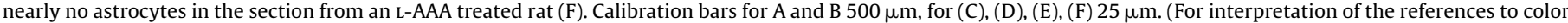
in this figure legend, the reader is referred to the web version of the article.)

imipramine $F(1,25)=56.50, p<0.0001$ and not significant interaction $F(2,25)=0.15, p=0.8642$.

\subsection{Western blot analysis}

\subsubsection{Effect of $\mathrm{L}-A A A$ administration on the GFAP and NeuN} protein level in the rat PFC at different time points and in different structures

The time course effect of L-AAA on the GFAP protein level in rat PFC is shown in Fig. 5. Significant decrease in the GFAP protein level was observed $72 \mathrm{~h}(p=0.0298)$ and $144 \mathrm{~h}(p=0.0195)$ after second L-AAA administration. No changes in the GFAP protein level were observed 7, 24 and $48 \mathrm{~h}$ after L-AAA treatment. L-AAA injection did not influence the NeuN level in PFC at any time points (data not shown). No changes in the GFAP level were found in the posterior cortical areas, hippocampus and amygdala (data not shown) after the toxin administration.

\subsubsection{Effect of $\mathrm{L}-A A A, \mathrm{DL}-A A A$ and imipramine administration on the GFAP protein level in the rat PFC}

The effects of L-AAA alone and combined administration of $\mathrm{L}$ AAA with imipramine on the GFAP protein level in PFC (144 h after the toxin injection) are shown in Fig. 6.

L-AAA administration induced a significant reduction in the GFAP protein level in the rat PFC (to $46 \%$ of control level). Imipramine alone had no effect on GFAP protein level however antagonized the effect induced by L-AAA. Two way ANOVA demonstrated no effect of L-AAA $[F(1,21)=2.18, p=0.1544]$; no effect of imipramine $[F(1,21)=0.33, p=0.569]$ and significant interaction $[F(1.21)=8.85, p=0.007]$. No significant changes were found 
Table 1

The effect of L-AAA and DL-AAA alone or in combined administration of L-AAA and MTEP on the locomotor activity in rats.

\begin{tabular}{lc}
\hline Treatment & Activity counts (5 min test) \\
\hline A & \\
Control & $662.08 \pm 66.1$ \\
L-AAA & $670.37 \pm 32.5$ \\
DL-AAA & $693.79 \pm 49.3$ \\
B & \\
Control & $583.7 \pm 10.08$ \\
Imipramine & $213.9 \pm 43.03^{\mathrm{a}}$ \\
L-AAA + imipramine & $311.5 \pm 81.43^{\mathrm{a}}$ \\
DL-AAA + imipramine & $212.9 \pm 28.25^{\mathrm{a}}$ \\
C & \\
Control & $622.5 \pm 64.99$ \\
MTEP $(10 \mathrm{mg} / \mathrm{kg})$ & $466.54 \pm 37.19$ \\
L-AAA + MTEP $(10 \mathrm{mg} / \mathrm{kg})$ & $487.5 \pm 45.55$ \\
\hline
\end{tabular}

Locomotor activity was examined; (A) $24 \mathrm{~h}$ after the second L-AAA or DL-AAA administration; (B) $72 \mathrm{~h}$ after the second administration of $\mathrm{L}-\mathrm{AAA}$ and $1 \mathrm{~h}$ after the last dose of imipramine (triplicate injections of imipramine $24,5,1 \mathrm{~h}$ before the test); (C) $72 \mathrm{~h}$ after the second administration of L-AAA and $20 \mathrm{~min}$ after the MTEP treatment. The values represent mean \pm SEM ( $n=6-8$ rats per group).

a $p<0.05$ vs control.

after DL-AAA alone and in combination with imipramine (data not shown).

\subsubsection{Effect of combined administration of $\mathrm{L}-A A A$ and MTEP on} the GFAP protein level in the rat PFC

The effects of L-AAA alone and the effect of combined administration of L-AAA with MTEP on the GFAP protein level in PFC (144 h after the toxin injection) are shown in Fig. 7.

L-AAA administration induced significant reduction in the GFAP protein level in the rat PFC (to $52,8 \%$ of control). MTEP antagonized the effect induced by L-AAA but did not change the GFAP protein level when given alone. Two way ANOVA demonstrated no effect of L-AAA $[F(1,30)=0.75, p=0.3523]$; no effect of MTEP $[F(1,30)=0.44$, $p=0.5102]$ and significant interaction $[F(1.30)=7.54, p=0.0101]$.

\subsection{Histological and immunohistochemical analysis}

\subsubsection{Effect of L-AAA and DL-AAA alone or in combined administration of $\mathrm{L}-A A A$ and MTEP on the number of GFAP-positive cells}

Histological analysis of sections stained with cresyl violet showed the proper localization of the injection sites (in $\mathrm{mPFC}$ ), and CV stained neurons were seen in the whole mPFC (Fig. 8A and B), also very near a scar (Fig. 8C and D) GFAP immunohistochemistry showed a decrease in a density of astrocytes in the mPFC of rats treated with L-AAA (Fig. $8 \mathrm{E}$ and F). Stereological counting showed a strong, significant decrease in the number of GFAP-immunoreactive (ir) astrocytes in MPFC after L-AAA in comparison to control rats (to $54,18 \%$ of control) (Fig. 9A). The effect of DL-AAA on the number of GFAP-ir astrocytes was weak and insignificant. The decreasing effect of L-AAA on the number of GFAP-ir cells was significantly inhibited by MTEP, reaching $81,2 \%$ of control (Fig. 9B). The glioprotective effect of MTEP found in stereological counting was confirmed by the morphological observation of astrocytes in the MPFC immunostained with an anti-GFAP antibody. A density of GFAP immunofluorescent astrocytes decreased by prior L-AAA administration was nearly normalized after MTEP treatment (Fig. 10).

\section{Discussion}

Our results indicate that gliotoxin induced degeneration of astrocytes in the rat medial prefrontal cortex may be used as a
A

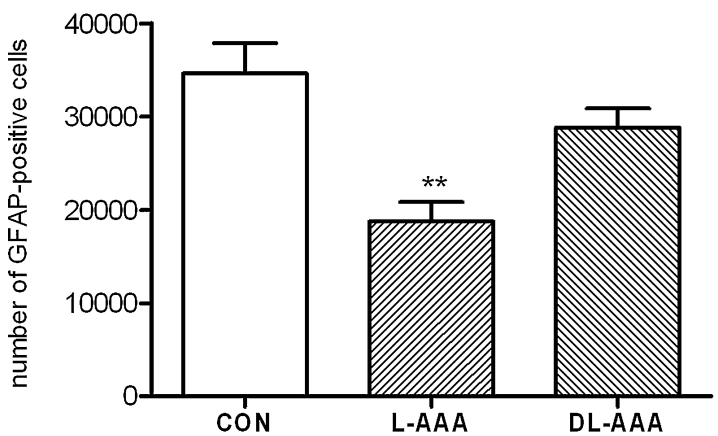

B

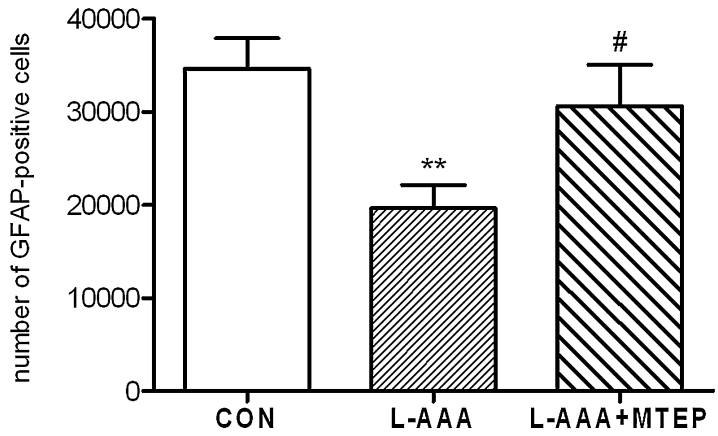

Fig. 9. The effect of L-AAA and DL-AAA administration (A) and the effect of combined administration of L-AAA and MTEP (B) on the number of GFAP positive cells in the rat $\mathrm{mPFC}$ counted by stereological method. L-AAA was administered twice into the rat $\mathrm{mPFC}$ at a dose of $100 \mu \mathrm{g} / 2 \mu \mathrm{l}$, on the first and the second day of experiment and MTEP $10 \mathrm{mg} / \mathrm{kg}$, i.p., was injected on day 5 (20 min before FST). Brains were taken for analysis on day 8 ( $144 \mathrm{~h}$ after the second toxin injection). The data are presented as the means $\pm \mathrm{SEM},(n=5-8$ rats per group $)$ and evaluated by one-way ANOVA followed by Tukey's multiple comparison test. $p<0.05$ was considered significant. ${ }^{* *} p<0.01$ vs control; ${ }^{\#} p<0.05$ vs L-AAA.

good experimental model of depression. The results are in line with the idea arising from numerous studies indicating that astrocyte dysfunction plays a crucial role in pathogenesis of depression. Actually, anhedonia was observed in rats after the blockade of astrocytic glutamate uptake in the prefrontal cortex [57]. Intracerebroventricular infusion of dihydrokainate, an astrocytic glutamate uptake blocker, also induced some signs of anhedonia observed in the intracranial stimulation and place conditioning tests [58]. The blockade of astrocytic glutamate uptake in the amygdala, a limbic structure engaged in the regulation of mood and anxiety has been reported to induce some behavioral effects characteristic of depressive-like symptoms [59]. Reduced glutamate transporter activity and expression was reported to occur in the hippocampus in the mouse stress model of depression and in the cortex in the learned helpless model in rats [60]. Also in human post mortem studies, downregulation of genes coding for astrocytic glutamate transporters was observed in the cingulate and prefrontal cortex of depressed subjects [61]. Dysfunction of astrocyte gap junction communication was also found in the rat prefrontal cortex after chronic unpredictable stress and it was reversed by treatment with antidepressants, moreover, the pharmacological gap junction blockade in the PFC induced depressive-like behavior in rats [62]. All these findings indicate that damage or impairment of proper function of astrocytes in the prefrontal cortex may be a good model of depression.

In our studies, we damaged astrocytes in the rat MPFC by the gliotoxin, alpha-aminoadipic acid (AAA). It was demonstrated to be a specific toxin for astrocytes already in 1971 by Olney and coworkers [63], and its specificity was confirmed in later years both in vivo 

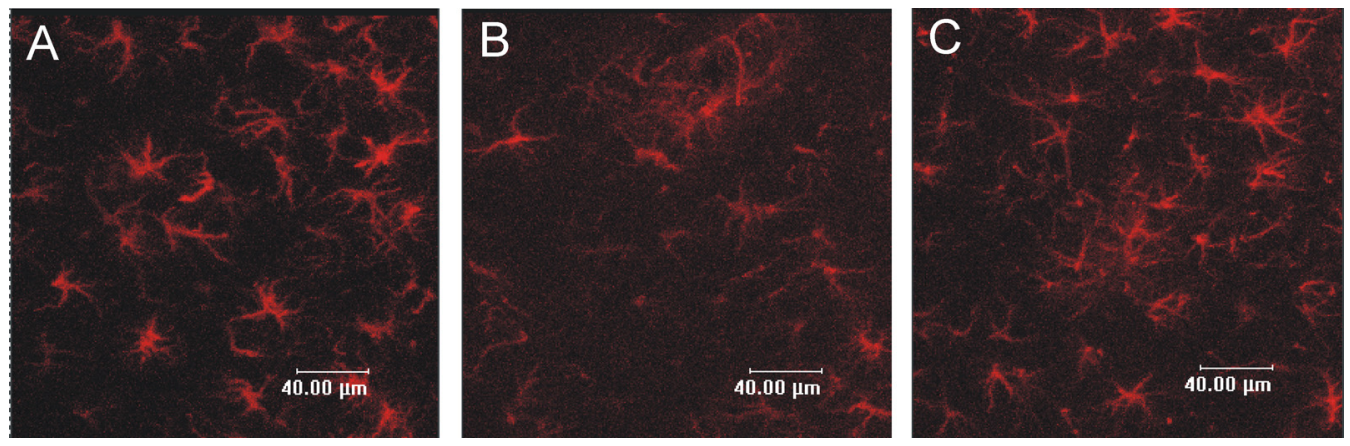

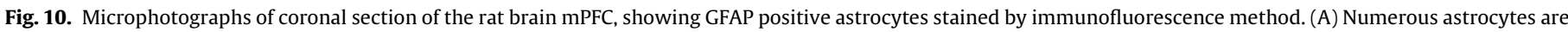

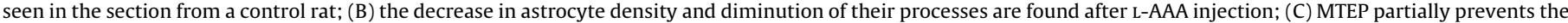
L-AAA effect: numerous astrocytes are visible like in the control section.

and in vitro [32,33,64]. It is taken up specifically by astrocytes and accumulating in these cells exerts its gliotoxic effect by interference with protein synthesis [31,34,65].

Studies of other authors concerning the effects of D- and L-isomers or racemic form of AAA gave conflicting, heterogeneous results. When administered subcutaneously into infant mice, it exerted a toxic effects in the arcuate hypothalamic nucleus, whereas D-AAA and DL-AAA induced, respectively, a mild to extreme gliotoxic but not neurotoxic damage and L-AAA induced not only gliotoxic but also some neurotoxic changes, moreover D-isomer had even anti-neurotoxic properties [32,64,66]. Similar results were obtained in astrocytes or mixed neuronal/astrocyte cultures [33] but additionally D-isomer appeared to be toxic only for mitotic cells [31]. The effect of AAA on astrocytes was also studied in adult rats after intracerebral injection into different brain structures. A single L-AAA injection into the amygdala induced loss of astrocytes and their markers (GFAP, S-100) in a wide area around the injection site, while neurons remained undamaged [67]. Astroglial degeneration was also observed after L-AAA injection into the striatum [68], substantia nigra and locus coeruleus [69]. On the other hand Saffran and Crutcher [70] failed to observe gliotoxic properties of L-AAA or DL-AAA in the hippocampus and striatum after injections into those structures. All the above mentioned studies, were focused only on the cellular effects of the toxins, and the authors did not examine their behavioral effects.

In our studies we used L-AAA and DL-AAA as a model of depression based on astrocyte ablation in the medial prefrontal cortex (mPFC). Such model was developed by Banasr and Duman [6]. The authors demonstrated that a double microinjection of gliotoxin L-alpha-aminoadipic acid (L-AAA) into the rat medial prefrontal cortex induced astroglial degeneration in the prefrontal cortex and triggered a depressive-like behavior similar to that observed after chronic unpredictable stress, a generally accepted model of depression. Doses of toxin and general schedule of our experiment were similar but we used not only L-AAA but also DL-AAA, as this racemic form has been suggested by some authors to be more specific for astrocytes (as already mentioned above).

Our present results showed that both gliotoxins L-AAA and DLAAA microinjected into the medial prefrontal cortex of the rat induced depressive-like behavioral effects, because an increase in immobility time in the forced swim test (FST) without changing locomotor activity was observed after these toxins. The effect was observed 24 and $72 \mathrm{~h}$ after the second gliotoxin injection but not after $144 \mathrm{~h}$. The results are in agreement with the findings of Banasr and Duman [6] who demonstrated L-AAA-induced depressive-like behavioral changes in rats in the sucrose preference test and forced swim test, in the novelty suppressed feeding model and active avoidance test at similar time points, but they did not study the behavioral effect after $144 \mathrm{~h}$. We found that not only L-AAA but also DL-AAA revealed similar depressive-like action and, moreover, the effect was prevented by the classical antidepressant drug, imipramine, used in doses and schedule typical for such studies [71]. These results indicate that the intra-mPFC gliotoxin injection may be a good model for studying antidepressant effects of drugs.

We verified also the effects of the gliotoxins on astrocytes by studying the appearance and the level of GFAP, a protein characteristic of astrocytes [72], using immunohistochemical and Western blot analysis. Both methods showed a decrease in GFAP-ir in the PFC after L-AAA microinjection, which indicated a damage of astrocytes. The effect is in line with the results of Banasr and Duman [6] who found a decrease in density of GFAP positive cells $144 \mathrm{~h}$ after L-AAA in chosen fields of the prefrontal cortex. DL-AAA displayed a tendency toward decreasing of the above parameters but the effect was statistically non-significant probably because of high variability of the results. For that reason, we have chosen L-AAA for further studies.

The Western blot analysis of the time-course of L-AAA-induced changes showed a progressive decrease in GFAP level displaying a non-significant lowering $48 \mathrm{~h}$ and a strong significant decrease 72 and $144 \mathrm{~h}$ after the second toxin injection. No such time-course studies were performed earlier. It is difficult to explain the discrepancy between low GFAP level $144 \mathrm{~h}$ after the toxin and the lack of depressive-like behavioral effect in the FST at the same time point. We may hypothesize that some compensatory changes might take place after the longer time period, even in other brain structures, which influenced animal behavior. This hypothesis seems to be supported by our preliminary findings which showed that GAD (glutamic acid decarboxylase) protein level, a marker of GABA neurons, increased in the hippocampus $144 \mathrm{~h}$ after the L-AAA injection (our unpublished observations). As depression is postulated to be a result of GABA/Glu imbalance with glutamatergic overactivity (see introduction), the activation of GABA function may have positive antidepressant effects on behavior.

We verified whether our gliotoxin model may be a useful model of depression. For this purpose we administered imipramine, a standard antidepressant drug, to L- and DL-AAA injected rats. Imipramine was given in triple doses which is routine treatment for screening antidepressive effects in FST (according to [73,74,75]). We evidenced that imipramine reversed the behavioral effects of both L-AAA and DL-AAA. The time of immobility decreased even below the control level. The imipramine effect seems to be specifically connected with an antidepressant action, because the drug decreased not increased, the locomotor activity.

We also studied whether imipramine prevented the gliotoxin induced astrocytic degeneration in the PFC using Western blot method. While imipramine reversed decreasing effect of L-AAA on GFAP level, the effect of DL-AAA was only weakly and 
non-significantly influenced (data not shown). Summing up, L-AAA toxin seems to be more promising as a model of depression.

There are no studies yet on the effect of imipramine or other antidepressants in the gliotoxic model both on behavior and on astrocyte density and GFAP protein level. However, in another model, chronic unpredictable stress in rats, both astrocyte pathology and depression-like behavior were reversed by antidepressants clomipramine, fluoxetine and magnolol [76-79]. The effect of antidepressant therapy on astrocytes was demonstrated both in experimental studies and in depressed patients [80].

We also examined whether the toxins used in our experiments, L-AAA and DL-AAA, killed neurons besides astrocytes. We did not observe neuronal loss in histological and Western blot studies. No diminution of nerve cells density was seen in brain sections from the $\mathrm{MPFC}$, stained with cresyl violet. Nerve cell bodies were observed even near the cannulae track and glial scar (Fig. 8A and B). Western Blot analysis of NeuN protein level was focused on the effect of L-AAA only, because, as mentioned above, L isomer of AAA was postulated by some authors to have some neurotoxic effects [32,33]. No changes in NeuN level were found during $7 \mathrm{~h}$ to $144 \mathrm{~h}$ after the toxin injection. This result is in agreement with the observations of Banasr and Duman [6] who found no noticeable neuronal loss in the prefrontal cortex after L-AAA in sections stained immunohistochemically with NeuN antibody.

As mentioned in the introduction, the glutamatergic overactivity has been postulated to be essential in pathogenesis of depression, and the model of astrocyte ablation is based on the dysregulation of the Glu/GABA balance. Therefore, in the present study, we used potential antidepressant compound, MTEP, to examine whether it can prevent the depressive-like effects of L-AAA toxin, as measured by behavioral test and astrocyte degeneration markers. MTEP is a highly selective negative allosteric modulator of mGlu5 receptors [81-83].

Antidepressant-like effect of MTEP was observed in previous studies in rat and mouse models. Pałucha et al. [47] showed that a single intraperitoneal injection of MTEP produced a significant, dose dependent decrease in the immobility time of mice in the tail-suspention test (TST) and chronic treatment with this compound inhibited bulbectomy induced hyperactivity in rats. Antidepressant-like effects of MTEP and other mGluR1 and mGluR5 antagonists were also demonstrated in the forced swim test in rats and the TST in mice [84-86]. Similarly, the other negative allosteric modulator of mGluR5, GRN-529, given orally, $1 \mathrm{~h}$ before the test, in a single dose into mice induced antidepressant-like and anxiolytic effects [83].

Our results indicate that MTEP possesses antidepressant-like activity also in the gliotoxin induced model of depression. This compound injected once $20 \mathrm{~min}$ before the forced swim test (FST), prevented the L-AAA induced increase in immobility time of rats. It also reversed the decreasing effect of L-AAA on GFAP level in PFC, measured $144 \mathrm{~h}$ after the toxin using Western blot method, and on the number of GFAP-ir cells determined by stereological counting.

It is especially interesting that the antidepressant-like effect of MTEP was found after a single injection. Till now, most of the studies concerning antidepressant drugs described that they were effective after chronic treatment only, both in human and animal experimental studies [87,88], but those studies were focused mainly on the drugs acting through the monoaminergic mechanisms and they needed weeks or months for developing their therapeutic effects. Moreover, about $30-50 \%$ of patients remains resistant to treatment [89]. On the other hand, the compounds acting by inhibition of glutamatergic activity, like NMDA receptor blockers (i.e. dizocilpin), revealed their antidepressant activity quickly after a single dose $[90,91]$. Metabotropic Glu5 receptors are anatomically and functionally coupled with NMDA receptors [92-94] and their activation potentiates NMDA receptor activity, so the mGluR5 antagonists indirectly inhibit them [95].

MTEP counteracted not only the depressive-like behavior after L-AAA but also prevented the astrocytic degenerations in the MPFC induced by the toxin. The mechanism of such protective effects is not clear but it may be connected with mGluR5 inhibition and in consequence with a diminution of NMDA receptor function. NMDA receptors are present on astrocytes and other glial cells [96]. Metabotropic Glu5 receptors are very abundant in astrocytes [97-101] and are found to be connected with NMDA receptor currents [102-104]. Inhibition of mGluR5 and NMDA receptors has neuroprotective and glioprotective effects $[51,105,106]$. It is worthwhile noting that L-AAA-induced astrocytic degeneration developed gradually (see results, Fig. 5), and at $72 \mathrm{~h}$ after the toxin, when MTEP was injected, the level of GFAP was still maintained at about $50 \%$, so the drug could affect these remaining astrocytes. Many studies have shown that antidepressants stimulate proliferation of astrocytes and production of trophic factors by these cells, such as BDNF, GDNF, FGF and others modulators which may restitute proper neuroglia network and their function [79,107-111]. Moreover, such effects may appear even after a short treatment and a single dose. The first molecular responses in ERK/MAPK signaling pathway in astrocytes may appear already after acute administration of desipramine or fluoxetine [110]. Primary cultures of rat astrocytes treated with fluoxetine revealed induction of MAPK, BDNF, GDNF and their receptor genes already $2 \mathrm{~h}$ after the beginning of the treatment [112]. Especially fast effects were found after the compounds acting through the glutamatergic receptors, but most of those studies investigated only behavioral changes, or receptor responses $[113,114]$. In clinical studies, rapid (during $2 \mathrm{~h}$ ) antidepressant effects were produced by the NMDA receptor antagonist ketamine or the low-trapping NMDA channel blocker AZD6765 [26,115]. The behavioral antidepressant-like effects were also revealed soon after a single mGluR5 antagonist treatment (as mentioned above).

Therefore we can hypothesize that antidepressant-like and antigliotoxic effects of MTEP demonstrated in the present gliotoxic model of depression, may result from its inhibitory action on mGluR5 and indirectly on NMDA receptors both in neurons and astrocytes. The astrocytes surviving after the toxin application may be stimulated for proliferation and production of growth factors and gliotransmitters which can improve structure and glianeuronal connections in the prefrontal cortex and restore proper behavior. However, this hypothesis needs further studies.

\section{Acknowledgments}

We wish to thank Assoc. Prof. Marzena Mackowiak for her valuable comments and assistance in using confocal microscopy.

This study was supported by the grant "Depressionmechanisms-therapy" POIG.01.01.02-12-004/09.

\section{References}

[1] Ongür D, Drevets WC, Price JL. Glial reduction in the subgenual prefrontal cortex in mood disorders. Proc Natl Acad Sci USA 1998;95:13290-5.

[2] Cotter D, Mackay D, Landau S, Kerwin R, Everall I. Reduced glial cell density and neuronal size in the anterior cingulate cortex in major depressive disorder. Arch Gen Psychiatry 2001;58:545-53.

[3] Sanacora G, Banasr M. From pathophysiology to novel antidepressant drugs: glial contributions to the pathology and treatment of mood disorders. Biol Psychiatry 2013;73:1172-9.

[4] Rajkowska G, Stockmeier CA. Astrocyte pathology in major depressive disorder: insights from human postmortem brain tissue. Curr Drug Targets 2013;14:1225-36.

[5] Rajkowska G, Miguel-Hidalgo JJ. Gliogenesis and glial pathology in depression. CNS Neurol Disord Drug Targets 2007;6:219-33.

[6] Banasr M, Duman RS. Glial loss in the prefrontal cortex is sufficient to induce depressive-like behaviors. Biol Psychiatry 2008;64:863-70. 
[7] Volterra A, Meldolesi J. Astrocytes, from brain glue to communication elements: the revolution continues. Nat Rev Neurosci 2005;6:626-40.

[8] Largo C, Cuevas P, Somjen GG, Martín del Río R, Herreras O. The effect of depressing glial function in rat brain in situ on ion homeostasis, synaptic transmission, and neuron survival. J Neurosci 1996;16:1219-29.

[9] Bergles DE, Jahr CE. Synaptic activation of glutamate transporters in hippocampal astrocytes. Neuron 1997;19:1297-308.

[10] Mennerick S, Zorumski CF. Glial contributions to excitatory neurotransmission in cultured hippocampal cells. Nature 1994;368:59-62.

[11] Araque A, Carmignoto G, Haydon PG. Dynamic signaling between astrocytes and neurons. Annu Rev Physiol 2001;63:795-813.

[12] Sofroniew MV, Vinters HV. Astrocytes: biology and pathology. Acta Neuropathol 2010;119:7-35.

[13] Araque A, Parpura V, Sanzgiri RP, Haydon PG. Tripartite synapses: glia, the unacknowledged partner. Trends Neurosci 1999;22:208-15.

[14] Perea G, Navarrete M, Araque A. Tripartite synapses: astrocytes process and control synaptic information. Trends Neurosci 2009;32:421-31.

[15] Haydon PG, Carmignoto G. Astrocyte control of synaptic transmission and neurovascular coupling. Physiol Rev 2006;86:1009-31.

[16] Anderson CM, Swanson RA. Astrocyte glutamate transport: review of properties, regulation, and physiological functions. Glia 2000;32:1-14.

[17] Wierońska JM, Pilc A. Metabotropic glutamate receptors in the tripartite synapse as a target for new psychotropic drugs. Neurochem Int 2009;55:85-97.

[18] Smiałowska M, Szewczyk B, Woźniak M, Wawrzak-Wleciał A, Domin H. Glial degeneration as a model of depression. Pharmacol Rep 2013;65:1572-9.

[19] Hashimoto K. Emerging role of glutamate in the pathophysiology of major depressive disorder. Brain Res Rev 2009;61:105-23.

[20] Hashimoto K. The role of glutamate on the action of antidepressants. Prog Neuropsychopharmacol Biol Psychiatry 2011;35:1558-68.

[21] Hashimoto K, Sawa A, Iyo M. Increased levels of glutamate in brains from patients with mood disorders. Biol Psychiatry 2007;62:1310-6.

[22] Levine J, Panchalingam K, Rapoport A, Gershon S, McClure RJ, Pettegrew JW. Increased cerebrospinal fluid glutamine levels in depressed patients. Biol Psychiatry 2000;47:586-93.

[23] Altamura CA, Mauri MC, Ferrara A, Moro AR, D’Andrea G, Zamberlan F. Plasma and platelet excitatory amino acids in psychiatric disorders. Am J Psychiatry 1993;150:1731-3.

[24] Mauri MC, Ferrara A, Boscati L, Bravin S, Zamberlan F, Alecci M, et al. Plasma and platelet amino acid concentrations in patients affected by major depression and under fluvoxamine treatment. Neuropsychobiology 1998;37:124-9.

[25] Mitani H, Shirayama Y, Yamada T, Maeda K, Ashby Jr CR, Kawahara R. Correlation between plasma levels of glutamate, alanine and serine with severity of depression. Prog Neuropsychopharmacol Biol Psychiatry 2006;30: 1155-8.

[26] Zarate Jr CA, Singh JB, Carlson PJ, Brutsche NE, Ameli R, Luckenbaugh DA, et al. A randomized trial of an $\mathrm{N}$-methyl-D-aspartate antagonist in treatmentresistant major depression. Arch Gen Psychiatry 2006;63:856-64.

[27] Maes M, Verkerk R, Vandoolaeghe E, Lin A, Scharpé S. Serum levels of excitatory amino acids, serine, glycine, histidine, threonine, taurine, alanine and arginine in treatment-resistant depression: modulation by treatment with antidepressants and prediction of clinical responsivity. Acta Psychiatr Scand 1998:97:302-8

[28] Bonanno G, Giambelli R, Raiteri L, Tiraboschi E, Zappettini S, Musazzi L, et al. Chronic antidepressants reduce depolarization-evoked glutamate release and protein interactions favoring formation of SNARE complex in hippocampus. J Neurosci 2005;25:3270-9.

[29] Tokarski K, Bobula B, Wabno J, Hess G. Repeated administration of imipramine attenuates glutamatergic transmission in rat frontal cortex. Neuroscience 2008:153:789-95

[30] Musazzi L, Milanese M, Farisello P, Zappettini S, Tardito D, Barbiero VS, et al. Acute stress increases depolarization-evoked glutamate release in the rat prefrontal/frontal cortex: the dampening action of antidepressants. PLOS ONE 2010;5:e8566.

[31] Brown DR, Kretzschmar HA. The glio-toxic mechanism of alpha-aminoadipic acid on cultured astrocytes. J Neurocytol 1998;27:109-18.

[32] Olney JW, de Gubareff T, Collins JF. Stereospecificity of the gliotoxic and antineurotoxic actions of alpha-aminoadipate. Neurosci Lett 1980;19:277-82.

[33] Huck S, Grass F, Hatten ME. Gliotoxic effects of alpha-aminoadipic acid on monolayer cultures of dissociated postnatal mouse cerebellum. Neuroscience 1984:12:783-91.

[34] Huck S, Grass F, Hörtnagl H. The glutamate analogue alpha-aminoadipic acid is taken up by astrocytes before exerting its gliotoxic effect in vitro. J Neurosci 1984:4:2650-7.

[35] Sanacora G, Zarate CA, Krystal JH, Manji HK. Targeting the glutamatergic system to develop novel, improved therapeutics for mood disorders. Nat Rev Drug Discov 2008;7:426-37.

[36] Skolnick P, Layer RT, Popik P, Nowak G, Paul IA, Trullas R. Adaptation of Nmethyl-D-aspartate (NMDA) receptors following antidepressant treatment: implications for the pharmacotherapy of depression. Pharmacopsychiatry 1996;29:23-6.

[37] Skolnick P. Antidepressants for the new millennium. Eur J Pharmacol 1999;375:31-40.

[38] Berman RM, Cappiello A, Anand A, Oren DA, Heninger GR, Charney DS, et al. Antidepressant effects of ketamine in depressed patients. Biol Psychiatry 2000;47:351-4.
[39] Kendell SF, Krystal JH, Sanacora G. GABA and glutamate systems as therapeutic targets in depression and mood disorders. Expert Opin Ther Targets 2005;9:153-68.

[40] Ostroff R, Gonzales M, Sanacora G. Antidepressant effect of ketamine during ECT. Am J Psychiatry 2005;162:1385-6.

[41] Chung C. New perspectives on glutamate receptor antagonists as antidepres sants. Arch Pharm Res 2012;35:573-7.

[42] Pochwat B, Pałucha-Poniewiera A, Szewczyk B, Pilc A, Nowak G. NMDA antagonists under investigation for the treatment of major depressive disorder. Expert Opin Investig Drugs 2014;12:1-12.

[43] Pin JP, Duvoisin R. The metabotropic glutamate receptors: structure and functions. Neuropharmacology 1995;34:1-26

[44] Conn PJ, Pin JP. Pharmacology and functions of metabotropic glutamate receptors. Annu Rev Pharmacol Toxicol 1997;37:205-37.

[45] Schoepp DD, Jane DE, Monn JA. Pharmacological agents acting at subtypes of metabotropic glutamate receptors. Neuropharmacology 1999;38:1431-76.

[46] Busse CS, Brodkin J, Tattersall D, Anderson JJ, Warren N, Tehrani L, et al The behavioral profile of the potent and selective mGlu5 receptor antagonist 3-[(2-methyl-1,3-thiazol-4-yl)ethynyl]pyridine (MTEP) in rodent models of anxiety. Neuropsychopharmacology 2004;29:1971-9.

[47] Pałucha A, Brański P, Szewczyk B, Wierońska JM, Kłak K, Pilc A. Potentia antidepressant-like effect of MTEP, a potent and highly selective mGluR5 antagonist. Pharmacol Biochem Behav 2005;81:901-6.

[48] Pałucha-Poniewiera A, Wierońska JM, Brański P, Burnat G, Chruścicka B, Pilc A. Is the mGlu5 receptor a possible target for new antidepressant drugs. Pharmacol Rep 2013;65:1506-11

[49] Pałucha-Poniewiera A, Brański P, Wierońska JM, Stachowicz K, Sławińska A Pilc A. The antidepressant-like action of mGlu5 receptor antagonist, MTEP, in the tail suspension test in mice is serotonin dependent. Psychopharmacology (Berl) 2014;231:97-107.

[50] Stachowicz K, Gołembiowska K, Sowa M, Nowak G, Chojnacka-Wójcik E, Pilc A. Anxiolytic-like action of MTEP expressed in the conflict drinking Vogel test in rats is serotonin dependent. Neuropharmacology 2007;53:741-8.

[51] Domin H, Zięba B, Gołembiowska K, Kowalska M, Dziubina A, Śmiałowska M. Neuroprotective potential of mGluR5 antagonist MTEP: effects on kainate-induced excitotoxicity in the rat hippocampus. Pharmacol Rep 2010;62:1051-61.

[52] Paxinos G, Watson C. The rat brain in stereotaxic coordinates. 2nd ed. San Diego: Academic Press; 1986.

[53] Nowak G, Szewczyk B, Wieronska JM, Branski P, Palucha A, Pilc A, et al Antidepressant-like effects of acute and chronic treatment with zinc in forced swim test and olfactory bulbectomy model in rats. Brain Res Bull 2003;61:159-64

[54] Maćkowiak M, Bator E, Latusz J, Mordalska P, Wędzony K. Prenatal MAM administration affects histone $\mathrm{H} 3$ methylation in postnatal life in the rat medial prefrontal cortex. Eur Neuropsychopharmacol 2014;24:271-89.

[55] Sterio DC. The unbiased estimation of number and sizes of arbitrary particles using the disector. J Microsc 1984;134:127-36.

[56] Gundersen HJ, Jensen EB, Kiêu K, Nielsen J. The efficiency of systematic sampling in stereology - reconsidered. J Microsc 1999;193:199-211.

[57] John CS, Smith KL, Van't Veer A, Gompf HS, Carlezon Jr WA, Cohen BM, et al Blockade of astrocytic glutamate uptake in the prefrontal cortex induces anhedonia. Neuropsychopharmacology 2012:37:2467-75.

[58] Bechtholt-Gompf AJ, Walther HV, Adams MA, Carlezon Jr WA, Ongür D Cohen BM. Blockade of astrocytic glutamate uptake in rats induces signs of anhedonia and impaired spatial memory. Neuropsychopharmacology 2010;35:2049-59.

[59] Lee Y, Gaskins D, Anand A, Shekhar A. Glia mechanisms in mood regulation: a novel model of mood disorders. Psychopharmacology (Berl) 2007; 191:55-65

[60] Zink M, Vollmayr B, Gebicke-Haerter PJ, Henn FA. Reduced expression of glutamate transporters vGluT1, EAAT2 and EAAT4 in learned helpless rats, an animal model of depression. Neuropharmacology 2010;58:465-73.

[61] Chaudhry FA, Lehre KP, van Lookeren Campagne M, Ottersen OP, Danbolt NC, Storm-Mathisen J. Glutamate transporters in glial plasma membranes: highly differentiated localizations revealed by quantitative ultrastructural immunocytochemistry. Neuron 1995; 15:711-20.

[62] Sun JD, Liu Y, Yuan YH, Li J, Chen NH. Gap junction dysfunction in the prefrontal cortex induces depressive-like behaviors in rats. Neuropsychopharmacology 2012;37:1305-20.

[63] Olney JW, Ho OL, Rhee V. Cytotoxic effects of acidic and sulphur containing amino acids on the infant mouse central nervous system. Exp Brain Res 1971;14:61-76.

[64] Bruni JE, Vriend J. Effect of D,L-alpha-aminoadipate on the mediobasa hypothalamus and endocrine function in the rat. Acta Neuropatho 1984;64:129-38.

[65] Nishimura RN, Santos D, Fu ST, Dwyer BE. Induction of cell death by L-alphaaminoadipic acid exposure in cultured rat astrocytes: relationship to protein synthesis. Neurotoxicology 2000;21:313-20.

[66] Pannicke T, Stabel J, Heinemann U, Reichelt W. alpha-Aminoadipic acid blocks the $\mathrm{Na}(+)$-dependent glutamate transport into acutely isolated Müller glia cells from guinea pig retina. Pflugers Arch 1994;429:140-2.

[67] Khurgel M, Koo AC, Ivy GO. Selective ablation of astrocytes by intracerebra injections of alpha-aminoadipate. Glia 1996;16:351-8.

[68] Takada M, Hattori T. Fine structural changes in the rat brain after loca injections of gliotoxin, alpha-aminoadipic acid. Histol Histopathol 1986;1: 271-5. 
[69] Chang FW, Wang SD, Lu KT, Lee EH. Differential interactive effects of gliotoxin and MPTP in the substantia nigra and the locus coeruleus in BALB/c mice. Brain Res Bull 1993;31:253-66.

[70] Saffran BN, Crutcher KA. Putative gliotoxin, alpha-aminoadipic acid, fails to kill hippocampal astrocytes in vivo. Neurosci Lett 1987;81:215-20.

[71] Kroczka B, Branski P, Palucha A, Pilc A, Nowak G. Antidepressant-like properties of zinc in rodent forced swim test. Brain Res Bull 2001;55:297-300.

[72] Sofroniew MV, Vinters HV. Astrocytes: biology and pathology. Acta Neuropathol 2010;119:7-35

[73] Porsolt RD, Anton G, Blavet N, Jalfre M. Behavioural despair in rats: a new model sensitive to antidepressant treatments. Eur J Pharmacol 1978;47:379-91.

[74] Rogóz Z, Budziszewska B, Kubera M, Basta-Kaim A, Jaworska-Feil L, Skuza $G$, et al. Effect of combined treatment with imipramine and metyrapone on the immobility time, the activity of hypothalamo-pituitary-adrenocortical axis and immunological parameters in the forced swimming test in the rat. J Physiol Pharmacol 2005;56:49-61.

[75] Papp M, Wieronska J. Antidepressant-like activity of amisulpride in two animal models of depression. J Psychopharmacol 2000;14:46-52.

[76] Li LF, Yang J, Ma SP, Qu R. Magnolol treatment reversed the glial pathology in an unpredictable chronic mild stress-induced rat model of depression. Eur J Pharmacol 2013;711:42-9.

[77] Liu Q, Li B, Zhu HY, Wang YQ Yu J, Wu GC. Clomipramine treatment reversed the glial pathology in a chronic unpredictable stress-induced rat model of depression. Eur Neuropsychopharmacol 2009;19:796-805.

[78] Czéh B, Simon M, Schmelting B, Hiemke C, Fuchs E. Astroglial plasticity in the hippocampus is affected by chronic psychosocial stress and concomitant fluoxetine treatment. Neuropsychopharmacology 2006;31:1616-26.

[79] Czéh B, Müller-Keuker JI, Rygula R, Abumaria N, Hiemke C, Domenici E, et al. Chronic social stress inhibits cell proliferation in the adult medial prefrontal cortex: hemispheric asymmetry and reversal by fluoxetine treatment. Neuropsychopharmacology 2007;32:1490-503.

[80] Czéh B, Di Benedetto B. Antidepressants act directly on astrocytes: evidences and functional consequences. Eur Neuropsychopharmacol 2013;23:171-85.

[81] Anderson JJ, Rao SP, Rowe B, Giracello DR, Holtz G, Chapman DF, et al. [3H]Methoxymethyl-3-[(2-methyl-1,3-thiazol-4-yl)ethynyl]pyridine binding to metabotropic glutamate receptor subtype 5 in rodent brain: in vitro and in vivo characterization. J Pharmacol Exp Ther 2002;303:1044-51.

[82] Cosford ND, Roppe J, Tehrani L, Schweiger EJ, Seiders TJ, Chaudary A, et al. $[3 \mathrm{H}]-$ methoxymethyl-MTEP and [3H]-methoxy-PEPy: potent and selective radioligands for the metabotropic glutamate subtype 5 (mGlu5) receptor. Bioorg Med Chem Lett 2003;13:351-4.

[83] Hughes ZA, Neal SJ, Smith DL, Sukoff Rizzo SJ, Pulicicchio CM, Lotarski S, et al. Negative allosteric modulation of metabotropic glutamate receptor 5 results in broad spectrum activity relevant to treatment resistant depression. Neuropharmacology 2013;66:202-14.

[84] Tatarczyńska E, Klodzińska A, Chojnacka-Wójcik E, Palucha A, Gasparini F, Kuhn R, et al. Potential anxiolytic- and antidepressant-like effects of MPEP, a potent, selective and systemically active mGlu5 receptor antagonist. $\mathrm{Br} \mathrm{J}$ Pharmacol 2001;132:1423-30.

[85] Li X, Need AB, Baez M, Witkin JM. Metabotropic glutamate 5 receptor antagonism is associated with antidepressant-like effects in mice. J Pharmacol Exp Ther 2006;319:254-9.

[86] Belozertseva IV, Kos T, Popik P, Danysz W, Bespalov AY. Antidepressant-like effects of mGluR1 and mGluR5 antagonists in the rat forced swim and the mouse tail suspension tests. Eur Neuropsychopharmacol 2007;17:172-9.

[87] Slattery DA, Hudson AL, Nutt DJ. Invited review: the evolution of antidepressant mechanisms. Fundam Clin Pharmacol 2004;18:1-21.

[88] Duman RS. Neurobiology of stress, depression, and rapid acting antidepressants: remodeling synaptic connections. Depress Anxiety 2014;31:291-6.

[89] Lang UE, Borgwardt S. Molecular mechanisms of depression: perspectives on new treatment strategies. Cell Physiol Biochem 2013;31:761-77.

[90] Zarate Jr CA, Mathews DC, Furey ML. Human biomarkers of rapid antidepressant effects. Biol Psychiatry 2013;73:1142-55.

[91] Szewczyk B, Pałucha-Poniewiera A, Poleszak E, Pilc A, Nowak G. Investigational NMDA receptor modulators for depression. Expert Opin Investig Drugs 2012;21:91-102.

[92] Tu JC, Xiao B, Naisbitt S, Yuan JP, Petralia RS, Brakeman P, et al. Coupling of mGluR/Homer and PSD-95 complexes by the Shank family of postsynaptic density proteins. Neuron 1999;23:583-92.

[93] Xiao B, Tu JC, Petralia RS, Yuan JP, Doan A, Breder CD, et al. Homer regulates the association of group 1 metabotropic glutamate receptors with multivalent complexes of homer-related, synaptic proteins. Neuron 1998;21: $707-16$.

[94] Jin DZ, Guo ML, Xue B, Mao LM, Wang JQ. Differential regulation of CaMKII $\alpha$ interactions with mGluR5 and NMDA receptors by $\mathrm{Ca}(2+)$ in neurons. J Neurochem 2013;127:620-31.

[95] Doherty AJ, Palmer MJ, Bortolotto ZA, Hargreaves A, Kingston AE, Ornstein PL, et al. A novel, competitive mGlu(5) receptor antagonist (LY344545) blocks DHPG-induced potentiation of NMDA responses but not the induction of LTP in rat hippocampal slices. Br J Pharmacol 2000;131:239-44.

[96] Dzamba D, Honsa P, Anderova M. NMDA receptors in glial cells: pending questions. Curr Neuropharmacol 2013;11:250-62.

[97] Balázs R, Miller S, Romano C, de Vries A, Chun Y, Cotman CW. Metabotropic glutamate receptor mGluR5 in astrocytes: pharmacological properties and agonist regulation. J Neurochem 1997;69:151-63.

[98] Zhang Y, Rodriguez AL, Conn PJ. Allosteric potentiators of metabotropic glutamate receptor subtype 5 have differential effects on different signaling pathways in cortical astrocytes. J Pharmacol Exp Ther 2005;315:1212-9.

[99] Paquet M, Ribeiro FM, Guadagno J, Esseltine JL, Ferguson SS, Cregan SP. Role of metabotropic glutamate receptor 5 signaling and homer in oxygen glucose deprivation-mediated astrocyte apoptosis. Mol Brain 2013;6:9.

[100] Mishra A, Mishra R, Gottschalk S, Pal R, Sim N, Engelmann J, et al. Microscopic visualization of metabotropic glutamate receptors on the surface of living cells using bifunctional magnetic resonance imaging probes. ACS Chem Neurosci 2014;5:128-37.

[101] Tamura A, Yamada N, Yaguchi Y, Machida Y, Mori I, Osanai M. Both neurons and astrocytes exhibited tetrodotoxin-resistant metabotropic glutamate receptor-dependent spontaneous slow $\mathrm{Ca}^{2+}$ oscillations in striatum. PLOS ONE 2014;9:e85351.

[102] Lea PM, Custer SJ, Vicini S, Faden AI. Neuronal and glial mGluR5 modulation prevents stretch-induced enhancement of NMDA receptor current. Pharmacol Biochem Behav 2002;73:287-98.

[103] D’Ascenzo M, Fellin T, Terunuma M, Revilla-Sanchez R, Meaney DF, Auberson YP, et al. mGluR5 stimulates gliotransmission in the nucleus accumbens. Proc Natl Acad Sci USA 2007;104:1995-2000.

[104] Cleva RM, Olive MF. Positive allosteric modulators of type 5 metabotropic glutamate receptors (mGluR5) and their therapeutic potential for the treatment of CNS disorders. Molecules 2011;16:2097-106.

[105] Domin H, Kajta M, Smiałowska M. Neuroprotective effects of MTEP, a selective mGluR5 antagonists and neuropeptide $\mathrm{Y}$ on the kainate-induced toxicity in primary neuronal cultures. Pharmacol Rep 2006;58:846-58.

[106] Abushik PA, Niittykoski M, Giniatullina R, Shakirzyanova A, Bart G, Fayuk D, et al. The role of NMDA and mGluR5 receptors in calcium mobilization and neurotoxicity of homocysteine in trigeminal and cortical neurons and glial cells. J Neurochem 2014;129:264-74.

[107] Takano K, Yamasaki H, Kawabe K, Moriyama M, Nakamura Y. Imipramine induces brain-derived neurotrophic factor mRNA expression in cultured astrocytes. J Pharmacol Sci 2012;120:176-86.

[108] Schmidt HD, Banasr M, Duman RS. Future antidepressant targets: neurotrophic factors and related signaling cascades. Drug Discov Today Ther Strateg 2008;5:151-6.

[109] Elsayed M, Banasr M, Duric V, Fournier NM, Licznerski P, Duman RS. Antidepressant effects of fibroblast growth factor- 2 in behavioral and cellular models of depression. Biol Psychiatry 2012;72:258-65.

[110] Di Benedetto B, Radecke J, Schmidt MV, Rupprecht R. Acute antidepressant treatment differently modulates ERK/MAPK activation in neurons and astrocytes of the adult mouse prefrontal cortex. Neuroscience 2013;232: 161-8.

[111] Fatemi SH, Folsom TD, Reutiman TJ, Pandian T, Braun NN, Haug K. Chronic psychotropic drug treatment causes differential expression of connexin 43 and GFAP in frontal cortex of rats. Schizophr Res 2008;104:127-34.

[112] Mercier G, Lennon AM, Renouf B, Dessouroux A, Ramaugé M, Courtin F, et al. MAP kinase activation by fluoxetine and its relation to gene expression in cultured rat astrocytes. J Mol Neurosci 2004;24:207-16.

[113] Chung C. New perspectives on glutamate receptor antagonists as antidepressants. Arch Pharm Res 2012;35:573-7.

[114] Maeng S, Zarate Jr CA, Du J, Schloesser RJ, McCammon J, Chen G, et al. Cellular mechanisms underlying the antidepressant effects of ketamine: role of alpha-amino-3-hydroxy-5-methylisoxazole-4-propionic acid receptors. Biol Psychiatry 2008;63:349-52.

[115] Zarate Jr CA, Mathews D, Ibrahim L, Chaves JF, Marquardt C, Ukoh I, et al. A randomized trial of a low-trapping nonselective N-methyl-D-aspartate channel blocker in major depression. Biol Psychiatry 2013;74:257-64. 